\section{Record of the Fungus Beetle Spathomeles ANCEPS (GORHAM) (COLEOPTERA: ENDOMYCHIDAE: LYCOPERDININAE) FROM KOLHAPUR, MAHARASHTRA, INDIA}

\section{Yogesh J. Koli ${ }^{1}$, Ganesh P. Bhawane ${ }^{2}$ \& H.V. Ghate ${ }^{3}$}

${ }^{1}$ Department of Zoology, Sant Rawool Maharaj College Kudal, Maharashtra 416520, India

${ }^{2}$ Department of Zoology, Shivaji University Kolhapur, Maharashtra 416004, India

${ }^{3}$ Department of Zoology (Retired), Modern College, Pune, Maharashtra 411005, India

${ }^{1}$ yogesh14_1985@rediffmail.com, 2drgpbhawane@rediffmail.com, ${ }^{3}$ hemantghate@gmail.com (corresponding author)

A small beetle with prominent tubercles on the elytra was recently collected in Kolhapur District. It was found in decaying wood. Convex body, typical pronotum and tubercles on the elytra suggested it to be a member of Endomychidae. Perusal of the classic 'Fauna of British India' volume on "Clavicornia" by Arrow (1925) for related beetles suggested the specimen to be close to Amphisternus Germar or Spathomeles Gerstaecker. Consulting the keys and detailed descriptions of the various species of both these genera in Arrow (1925), revealed the beetle to be Amphisternus anceps Gorham. Our specimen matches with all the characters given by Gorham (1895) in the original description, and subsequently by Arrow (1925), for this species. There is no illustration of this species in Gorham's paper or in Arrow's Fauna, but the descriptions are very good.

Gorham (1895) had described this species on the basis of a single male from 'Kanara' ('collector:

J.R.D. Bell') and mentioned this to be the only species of Amphisternus 'that is with pubescence'. Arrow (1925) added 'Nilgiri Hills' and Assam (Garo Hills, Tura) as additional localities. In his synopsis of Amphisternini, Strohecker (1964) placed this species in Spathomeles; a line drawing of lateral view of elytra given in that paper helped us to narrow down further the identity of this species. Strohecker added another locality for this species, namely Nepal, in the same paper.

A very recent annotated checklist of "Handsome Fungus Beetles" by Shockley, Tomaszewska \& McHugh (2009) also includes this species as Spathomeles anceps (Gorham). There are no synonyms for this species other than the original name, Amphisternus anceps.

There are apparently no other published records of the species and no full illustrations, though we have not been able to check all records. Dr. Floyd Shockley kindly provided an excellent illustration of a male of this species, from Dr. Strohecker's collection of images, and the identity of our species was further confirmed.
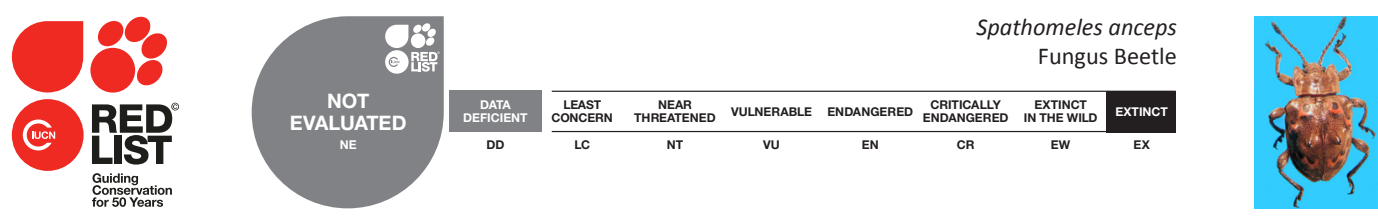

DOI: http://dx.doi.org/10.11609/JoTT.o4016.6477-9 | ZooBank: urn:Isid:zoobank.org:pub:F7B67B7B-B4A8-4992-8CCA-B4E7421A5AFF

Editor: Wioletta Tomaszewska, Museum and Institute of Zoology, Wilcza, Poland.

Date of publication: 26 October 2014 (online \& print)

Manuscript details: Ms \# 04016 | Received 02 May 2014 | Final received 05 September 2014 | Finally accepted 16 September 2014

Citation: Koli, Y.J., G.P. Bhawane \& H.V. Ghate (2014). Record of the Fungus Beetle Spathomeles anceps (Gorham) (Coleoptera: Endomychidae: Lycoperdininae) from Kolhapur, Maharashtra, India. Journal of Threatened Taxa 6(11): 6477-6479; http://dx.doi.org/10.11609/JoTT.04016.6477-9

Copyright: (c) Koli et al. 2014. Creative Commons Attribution 4.0 International License. JoTT allows unrestricted use of this article in any medium, reproduction and distribution by providing adequate credit to the authors and the source of publication.

Funding: UGC and CSIR, New Delhi (No. 37(1449)/10/EMR II).

Competing Interest: The authors declare no competing interests.

Acknowledgements: Authors are grateful to the authorities of Shivaji University, Kolhapur, and Modern College, Pune, for facilities and encouragement. Hemant Ghate is particularly grateful to Dr. Floyd Shockley (Smithsonian Institution, USA) for readily helping in identification by providing a very good image, and to Dr. Wioletta Tomaszewska (Museum and Institute of Zoology, Polish Academy of Sciences, Poland) for comments, literature and help in preparation of this note. We also thank Biodiversity Heritage Library people for making classics on taxonomy freely available on internet. Finally we thank Council of Scientific and Industrial Research (CSIR) and UGC SAP DRS Phase I, New Delhi for financial support under the project "Diversity of Coleopteran fauna of Kolhapur District", (No. 37(1449)/10/EMR II) 
The genus Spathomeles Gerstaecker has been redescribed in considerable detail recently and placed in the subfamily Lycoperdininae, of the family Endomychidae, by Tomaszewska (2005) and we could study most of the characters on the available single female specimen.

The species has been adequately described by Gorham (1895) and in Arrow (1925), hence only brief morphological characters and illustrations are provided in this note.

\section{Spathomeles anceps (Gorham)}

Specimen examined: Reg. No. Coleoptera, Endomychidae-1, one female from Shivaji University campus, Kolhapur $\left(16^{\circ} 40^{\prime} 40.70^{\prime \prime} \mathrm{E} \& 7^{\circ} 15^{\prime} 20.67^{\prime \prime} \mathrm{N}\right.$ elevation $608 \mathrm{~m}$ ), coll. Yogesh Koli (presently preserved in Modern College). Images prepared on Leica SMZ6, using Canon PowerShot S 50, were stacked using combine ZM freeware.

Beetle elongate oval, with very convex body, $10 \mathrm{~mm}$ long; ground colour dark brown to blackish with bilaterally symmetrical orange markings on elytra. Body covered all over with fine, short pubescence. Elytra with a pair of large and pair of small tubercles, the tips of large tubercles glistening black (Image 1). The elytral markings are as follow: each elytra has a small basal orange ring with a black spot within, the extension of this orange ring goes backward, lateral to the small elytral tubercle. In addition, there is a posterior wavy band of the same orange colour with four anterior and two posteriorly directed broad branches- the small cup-

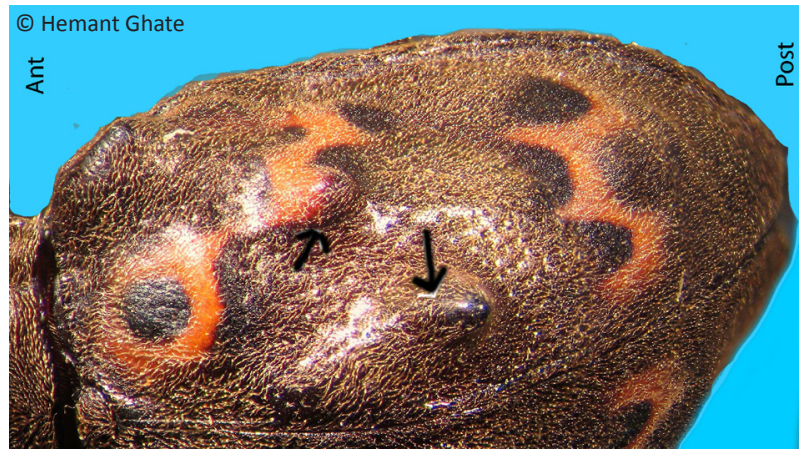

Image 2. Dorsolateral view of right elytron of Spathomeles showing tubercles (arrow) and the coloration in posterior half.

shaped areas between the anteriorly directed bands are black and visible only in lateral view (Image 2).

Head broadly triangular, retracted in prothorax; eyes large, coarsely facetted and obliquely oval, as seen from dorsal side. Antennae about half length of body, antennomeres relatively stout, with terminal three antennomeres forming a flat club. Prothorax transverse, almost rectangular; lateral edges very weakly sinuate, bordered; anterior angles produced forwards, rounded, reaching to almost anterior margin of head as seen from above; posterior angles almost rectangular; pronotal disc somewhat convex with a deep oval sunken area, just in front of the middle, and a shallow longitudinal median sulcus behind that reaches basal pronotal sulcus (Image 3).

Prosternal process (Image 4) moderately wide,

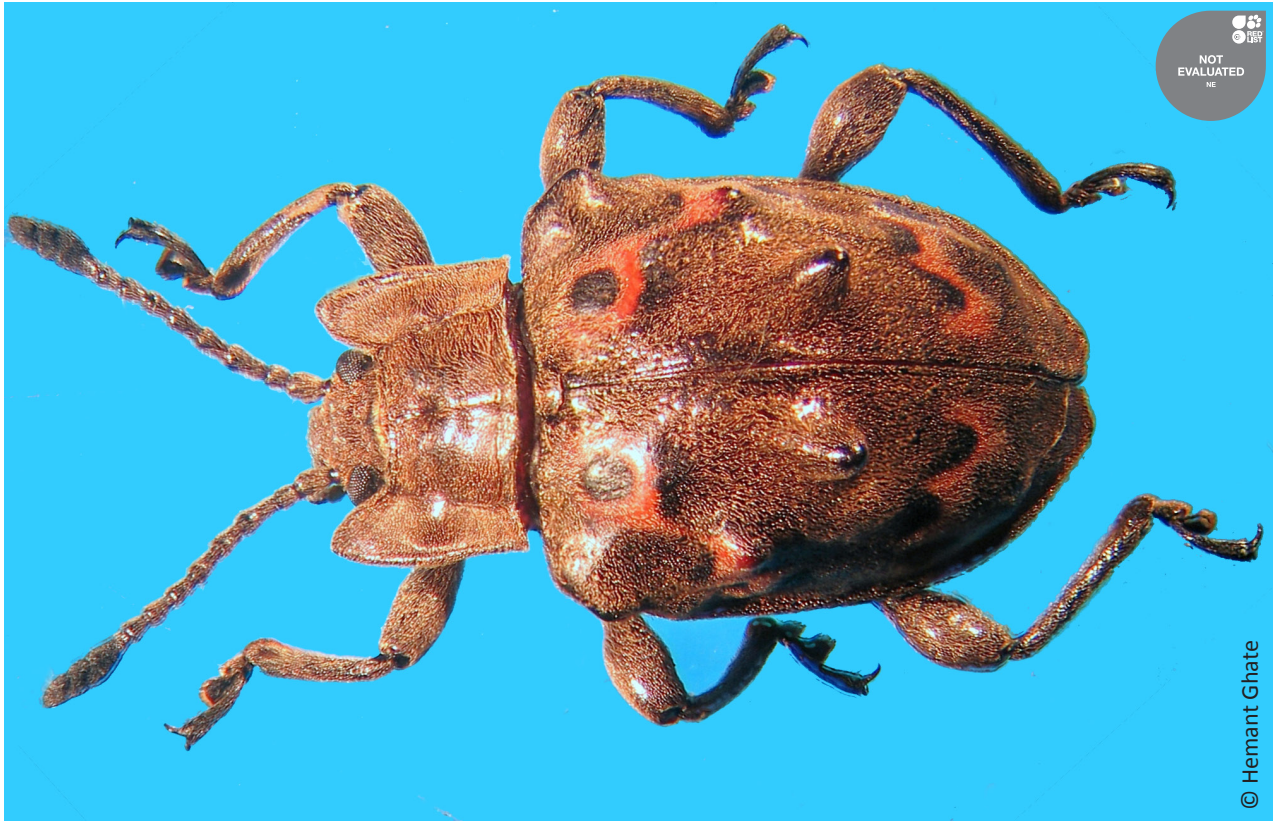

Image 1. Dorsal view of Spathomele anceps. 


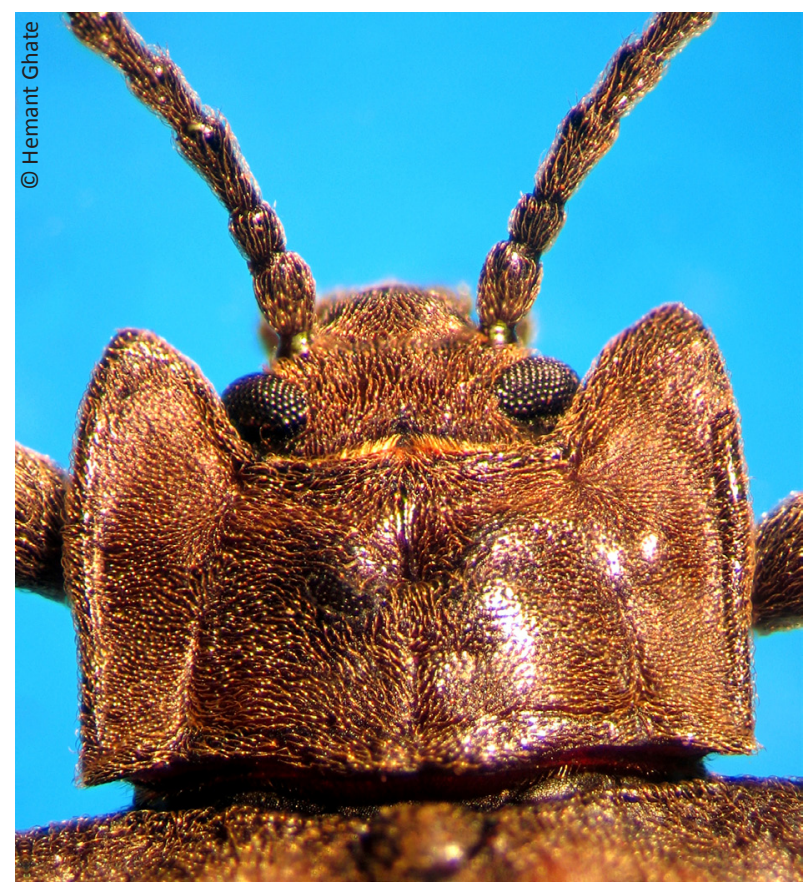

Image 3. Dorsal view of head and pronotum in Spathomeles.

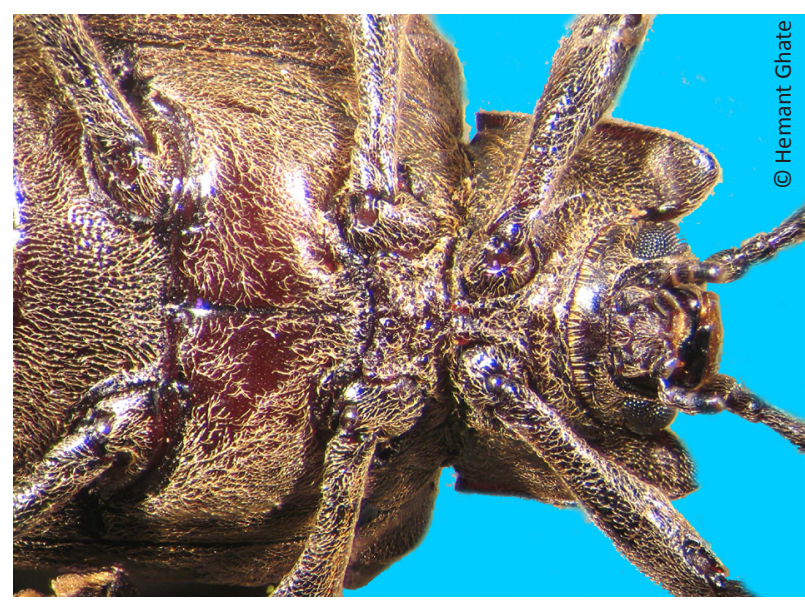

Image 4. Ventral view of the anterior half of Spathomeles showing prosternum.

somewhat rounded laterally and distinctly concave in the middle, projecting slightly beyond front coxae; mesoventral process almost rectangular, but angulate at anterior-lateral corners and moderately sinuate posteriorly; mesocoxae much more widely separated than procoxae; metaventrite transverse and somewhat flattish and sunken, with very small post-coxal pits and long but incomplete median sulcus / discrimen. Metacoxae separated much wider than pro- or mesocoxae.

Elytra finely and densely punctate, basal margins

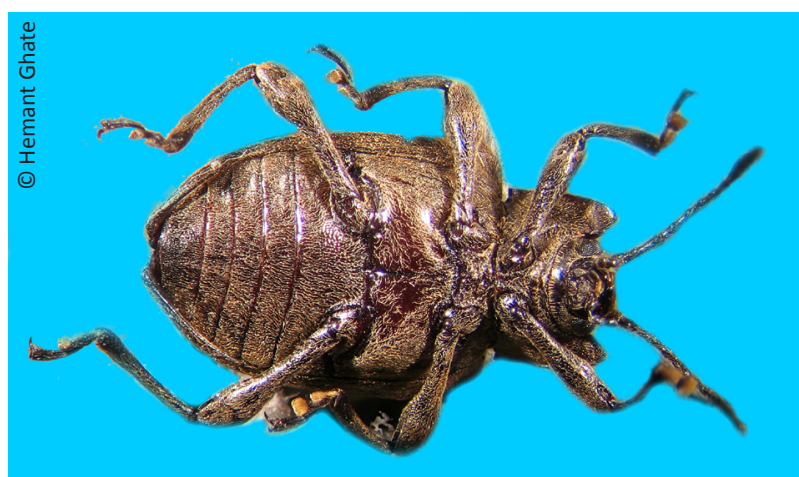

Image 5. Full ventral view of Spathomeles.

more or less straight; just behind the humeral angle the elytral side slightly produced laterally; elytral sides nearly parallel, from beyond humeral angles to slightly beyond the middle, then narrowing towards apices; very convex with two prominent elongate and two small rounded tubercles; apex truncate.

Legs long, moderately stout and setose; femora clavate with more than half of the proximal length slender, and the rest dilated; all tibia slightly curved on inside; terminal tarsomere very long in all tarsi. Abdomen with five ventrites. First ventrite much longer than the subsequent three ventrites; setae somewhat sparse on ventral side in general (Image 5).

Previously known from Nilgiri Hills in southern India and Assam in northeastern India; outside it has been recorded in Nepal. This is probably the first record of the species in Maharashtra. Since it is not known from any other localities, it is likely that the species is endemic to the Indian subcontinent. Overall, it may be said that these beautiful beetles need more attention.

\section{References}

Arrow, G.J. (1925). Fauna of British India Including Ceylon and Burma. Coleoptera: Clavicornia - Erotylidae, Languriidae and Endomychidae. Taylor and Francis, London, 416pp.

Gorham, H.S. (1895). List of the Coleoptera in the collection of H.E. Andrwes Esq. from India and Burma with descriptions of new species and notes. Families Malacodermata, Erotylidae-Endomychidae. Annales de La Societe Entomologique de Belgique. Trente neuvieme VI: 293-330.

Shockley, F.W., K.W. Tomaszewska \& J.V. Mchugh (2009). An annotated checklist of the handsome fungus beetles of the world (Coleoptera: Cucujoidea: Endomychidae). Zootaxa 1999: 1-113.

Strohecker, H.F. (1964). A synopsis of the Amphisternini (Coleoptera: Endomychidae) Pacific Insects 6(2): 319-357.

Tomaszewska, K.W. (2005). Phylogeny and generic classification of the subfamily Lycoperdininae with a re-analysis of the family Endomychidae (Coleoptera: Cucujoidea). Annales Zoologici 55(Supplement 1): 1-172. 